\title{
Incidence of hypoplastic posterior communicating artery and fetal posterior cerebral artery in Andhra population of India: a retrospective 3 -Tesla magnetic resonance angiographic study
}

\author{
Sharmila P Bhanu' ${ }^{1}$, Suneetha Pentyala ${ }^{2}$, Devi K Sankar ${ }^{1}$ \\ ${ }^{1}$ Department of of Anatomy, Narayana Medical College, Nellore, Andhra Pradesh, ${ }^{2}$ Department of of Radiology, Narayana Medical College \& General \\ Hospital, Nellore, Andhra Pradesh, India
}

\begin{abstract}
The posterior communicating arteries ( $\mathrm{PCoA})$ are important component of collateral circulation between the anterior and posterior part of circle of Willis (CW). The hypoplasia or aplasia of PCoA will reflect on prognosis of the neurological diseases. Precise studies of the incidence of hypoplastic PCoA in Andhra Pradesh population of India are hitherto unreported, since the present study was undertaken. Two hundred and thirty one magnetic resonance angiography (MRA) images were analyzed to identify the hypoplasia of PCoA and presence of fetal type of posterior cerebral artery (f-PCA) in patients with different neurological symptoms. All the patients underwent 3.0T MRI exposure. The results were statistically analysed. A total of 63 (27.3\%) PCoA hypoplasia and 13 cases with f-PCA (5.6\%) cases were identified. The hypoplastic PCoA was noted more in males than females $(P<0.05)$ and right side hypoplasia was common than the left $(P<0.04)$; bilateral hypoplasia of PCoA was seen in 37 cases out of 63 and is significant. The hypoplastic cases of the present study also were associated with variations of anterior cerebral arteries and one case was having vertebral artery hypoplasia. Incidence of PCoA as unilateral or bilateral with other associated anomalies of CW is more prone to develop stroke, migraine and cognitive dysfunction. Knowledge of these variations in the PCoA plays a pivotal role in diagnoses of neurological disorders and in neurovascular surgeries and angiographic point of view.
\end{abstract}

Key words: Posterior communicating artery, Hypoplastic, Posterior cerebral artery, Circle of Willis, Cerebral artery

Received March 20, 2020; Revised May 16, 2020; Accepted May 21, 2020

\section{Introduction}

Detailed anatomy of the circle of Willis (CW) or circulus

\section{Corresponding author:}

Devi K Sankar (iD

Department of of Anatomy, Narayana Medical College, Chinthareddypalem,

Nellore, Andhra Pradesh 524003, India

E-mail: lesanshar@gmail.com arteriosus is important in the field of neurology, neurosurgery and anatomy. The $\mathrm{CW}$ is the main arterial structure located at base of the brain that establishes collateral circulation to the brain and surrounding structures. The arterial circle is formed by internal carotid and vertebro-basilar systems comprising anterior cerebral artery (ACA), proximal segments of internal carotid and proximal segments of posterior cerebral arteries from basilar artery. The CW normally equalizes the blood flow to various parts of the brain. But a complete CW is seen in minority of the population and as 
age advances it shows different types of anatomical variations in its branches since birth [1].

Posterior communicating artery (PCoA), branch of internal carotid artery acts as a significant anastomotic channel between anterior and posterior cerebral circulations [2]. Each PCoA runs postero-medially and anastomose at the junction between pre (P1) and post-communicating (P2) segments of ipsilateral posterior cerebral artery (PCA) [3]. The PCoA occasionally continues as PCA, called as fetal PCA (f-PCA) with a complete absence of P1 segment [4]. Its occurrence may be unilateral or bilateral, and in these conditions, the PCoA is bigger than the normal [5].

The PCoA establishes the collateral circulation through its penetrating branches which supply the ventrolateral and dorsomedial thalamic nuclei, tuber cinereum, mamillary bodies, and cerebral peduncles [6]. The PCoA hypoplasia and aplasia can be congenital variations characterized by a narrow or poorly developed artery with limited blood flow [1]. As PCoA render a vital communication between internal carotid and vertebro-basilar system, occlusion, aplasia or hypoplasia of this artery can significantly affect the vascularity of brain. In bilateral aplasia or hypoplasia, there will be a bilateral interruption of blood supply to the cerebellum. These anatomical variations reduce the accessibility of collateral vessels and its circulation. Hence identification of such variations is important in the evaluation of cerebral vascular morbidity and its allied treatments. The objective of the present study is to observe the variations in the arrangement of PCoA of CW.

\section{Materials and Methods}

The present study was a retrospective analysis of magnetic resonance angiography (MRA) of CW on 231 patients, which included 154 males and 77 females. The age of the patients with hypoplastic PCoA was minimum of 25 years and maximum of 79 years. The study was approved by the institutional ethical committee and clinical variables were abstracted from Institutional Neurology review board. The cases were obtained between the years 2016-2019 from the patients who had evidence of cerebral ischemic stroke (CIS), history of severe migraine, less hearing sense, dim vision and mild focal neurological deficit.

A time of flight (TOF)-MRA technique was used and the study was conducted and analyzed in the departments of radiology, anatomy, and neurology. All the patients underwent 3D TOF-MRA using 3.0T MRI machine (3.0T system, GE Discovery MR750w 3.0Tesla; GE Healthcare, Milwaukee, WI, USA) and imaging parameters used were (1) repetition time was 30 milliseconds and echo time was $2.7-3.1$ milliseconds, (2) flip angle was $20^{\circ}$, (3) $200 \mathrm{~mm}$ field of view, (4) section thickness was $1.4 \mathrm{~mm}$, and (5) the imaging time was approximately 4.49 minutes. The images obtained were processed using a maximum intensity projection algorithm to create an angiogram like image [7]. The reconstructed images were then analyzed to detect the hypoplastic $(<1 \mathrm{~mm}$ in diameter) or aplastic PCoA and with or without the f-PCA. The PCoA with aneurysms were excluded from the study. Other than hypoplasia of PCoA, anomalies such as hypoplasia or aplasia of other cerebral arteries and its branches were also noted. The data obtained were analyzed with Statistical Package for Social Sciences software (IBM SPSS Statistics for Windows, Version 25.0. IBM Corp., Armonk, NY, USA). The statistical dependencies between age, side and sex were measured using the Student t-test. The differences between the male and female PCoA hypoplasia were assessed in relation to side using the Chi-square test. Probability values of $P>0.05$ were considered as statistically significant.

\section{Results}

In the present study, out of 231 patients, 63 patients (27.3\%)

Table 1. Independent sample-T and ANOVA tests to find the differences between the sex and side in patients with hypoplastic posterior communicating artery

\begin{tabular}{|c|c|c|c|c|c|c|c|c|c|c|c|c|}
\hline \multirow{2}{*}{$\begin{array}{c}\text { Variable } \\
\text { Side }\end{array}$} & \multicolumn{4}{|c|}{ Male (in years) } & \multicolumn{4}{|c|}{ Female (in years) } & \multicolumn{2}{|r|}{ Total } & \multirow{2}{*}{ t-value } & \multirow{2}{*}{$P$-value } \\
\hline & $\mathrm{N}$ & Mean \pm SD & Min & $\operatorname{Max}$ & $\mathrm{N}$ & Mean \pm SD & Min & Max & $\mathrm{N}$ & Mean \pm SD & & \\
\hline Left side & 6 & $62.50 \pm 14.38$ & 45 & 79 & 4 & $48.50 \pm 15.35$ & 29 & 65 & 10 & $56.90 \pm 15.67$ & 1.470 & $0.180^{\mathrm{a})}$ \\
\hline Right side & 9 & $69.00 \pm 6.63$ & 60 & 74 & 7 & $55.29 \pm 17.30$ & 25 & 74 & 16 & $63.00 \pm 13.88$ & 2.197 & $0.045^{\mathrm{b})}$ \\
\hline Bilateral & 24 & $65.04 \pm 6.04$ & 52 & 79 & 13 & $60.23 \pm 6.39$ & 52 & 75 & 37 & $63.35 \pm 6.81$ & 2.153 & $0.038^{\mathrm{b})}$ \\
\hline Grand total & 39 & $65.56 \pm 8.18$ & 45 & 79 & 24 & $56.83 \pm 12.22$ & 25 & 75 & 63 & $62.24 \pm 10.71$ & 3.399 & $0.001^{c)}$ \\
\hline F-value & \multicolumn{4}{|c|}{0.956} & & \multicolumn{2}{|c|}{2.281} & & \multicolumn{2}{|r|}{1.507} & & \\
\hline$P$-value & \multicolumn{4}{|c|}{$0.393^{\mathrm{a})}$} & & \multicolumn{2}{|c|}{$0.122^{\mathrm{a})}$} & & & $0.230^{\mathrm{a})}$ & & \\
\hline
\end{tabular}

$\mathrm{N}$, number of cases observed; SD, standard deviation; Min, minimum; Max, maximum; $\mathrm{t}$, results of independent sample $\mathrm{t}$-test; $P$, difference between the sex, age and side $\& P<0.05$ is considered significant; $\mathrm{F}$ and $P$ are the results of ANOVA. ${ }^{\text {a) }}$ Not significant; ${ }^{\text {b) }}$ Significant; ${ }^{\text {c) }}$ Highly significant. 
showed the incidence of hypoplastic PCoA in MRA pictures, which included 39 males (16.9\%) and 24 females (10.4\%). The mean age of males and females were $65.56 \pm 8.18$ and
$56.83 \pm 12.22$ respectively (Table 1 ). The hypoplasia of PCoA was noted more in males than females $(P<0.05)$. Out of 63 PCOA hypoplastic, unilateral cases included 26 of which
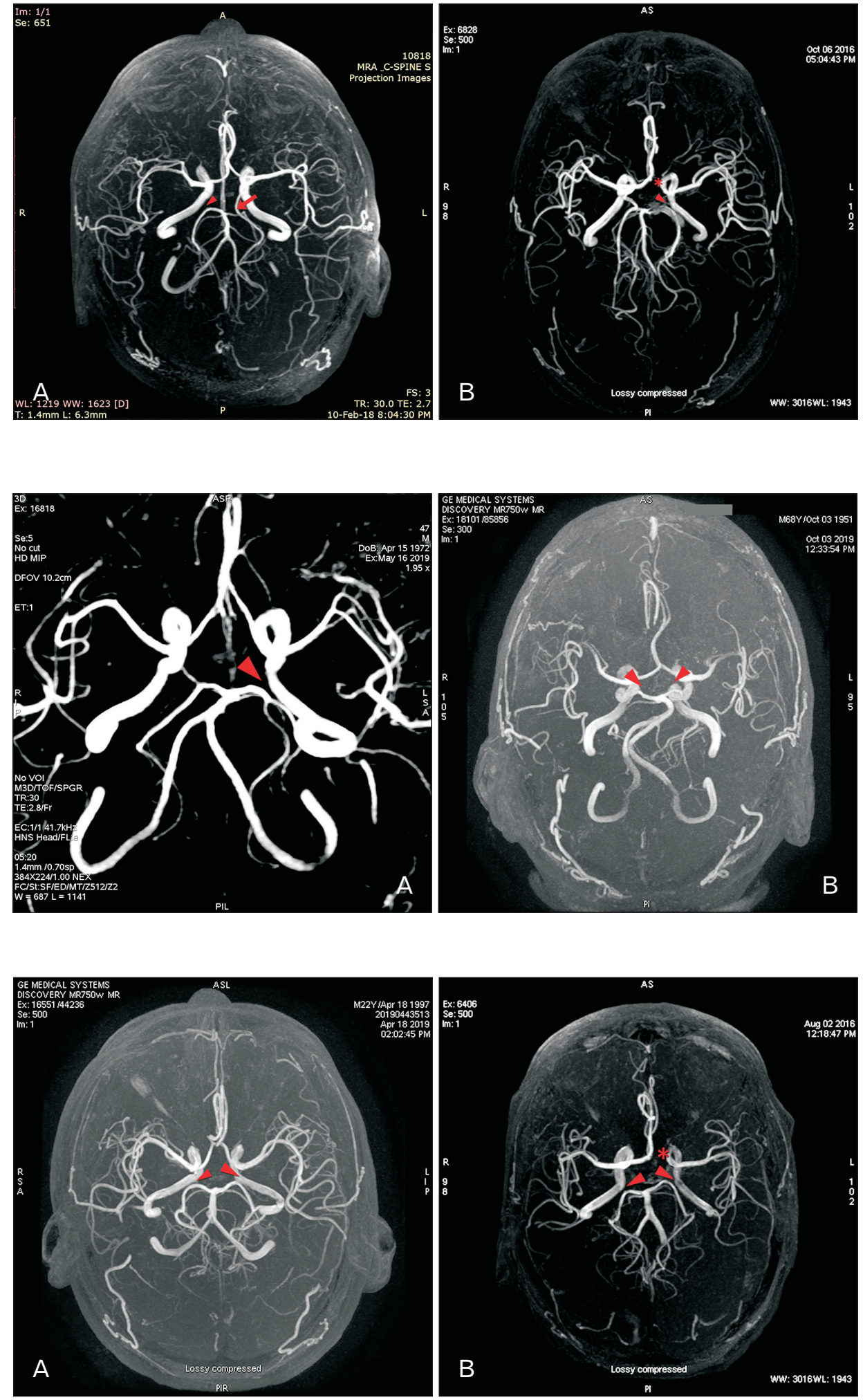

Fig. 3. MRA images showing (A) bilateral PCoA hypoplasia (arrowheads); (B) bilateral PCoA hypoplasia (arrowheads) with hypoplastic A1 segment of anterior cerebral artery (asterisk). MRA, magnetic resonance angiography; PCoA, posterior communicating artery. 
right side PCoA hypoplasia (Fig. 1A) in males was 9 and in females 7 while the left side (Figs. 1B, 2A, 4B) was found to be 6 in males and 4 in females. The right sided hypoplasia was significant $(P<0.04)$ than the left in the present study. The bilateral hypoplasia (Figs. 2B, 3A, 3B, 4A) was seen in 37 patients (58.7\%), which included 24 males and 13 females and is found significant. Overall the statistical association between the hypoplasia of PCoA in relation to sex and side was found to be highly significant $(P<0.001)$ (Table 2$)$.

The f-PCA was observed in 13 (5.6\%) cases which is more on right (73.0\%) (Fig. 4B) than left side (62.6\%) (Fig. 1B) and the incidence is more or less equal in both males and females with no statistical significance $(P<0.05)$ (Table 3$)$.

Apart from hypoplasia of PCoA and f-PCA, some of the cases also presented with other arterial anomalies. Out of 10 left PCoA hypoplastic cases, 2 cases were associated with hypoplastic right vertebral artery (Fig. 4A, B), right A1 segment of ACA and right f-PCA (Fig. 4B) and left A1 segment of ACA (Fig. 1B). Similarly on right PCoA hypoplasia, 6 out of 16 cases were identified with hypoplastic A1 segment of ACA. In total of 37 bilateral hypoplastic PCoA, 4 were associated with hypoplastic A1 segment of ACA (Fig. 1B) and one cases was found to be associated with vertebral artery hypoplasia (Fig. 4A).

\section{Discussion}

The CW is the main source of blood supply to major parts of the brain, in which various patterns of its formation and number of anatomical variations have been reported till date in the literature. In most variations of the $\mathrm{CW}$, brain function may not be affected due to the collateral circulation and compensation of the blood supply from the contralateral side. In a study of 1,000 brain specimens, $45.2 \%$ of typical and $54.8 \%$ variations of the $\mathrm{CW}$ were reported [8].

The PCoA is an important artery establishing collateral

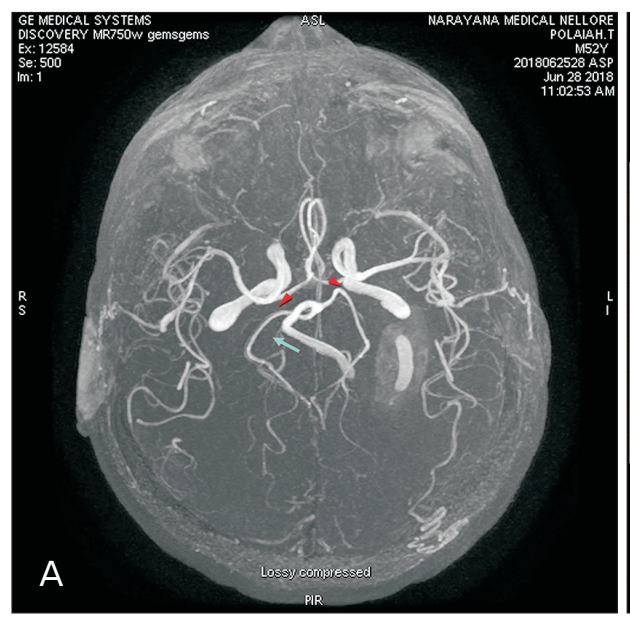

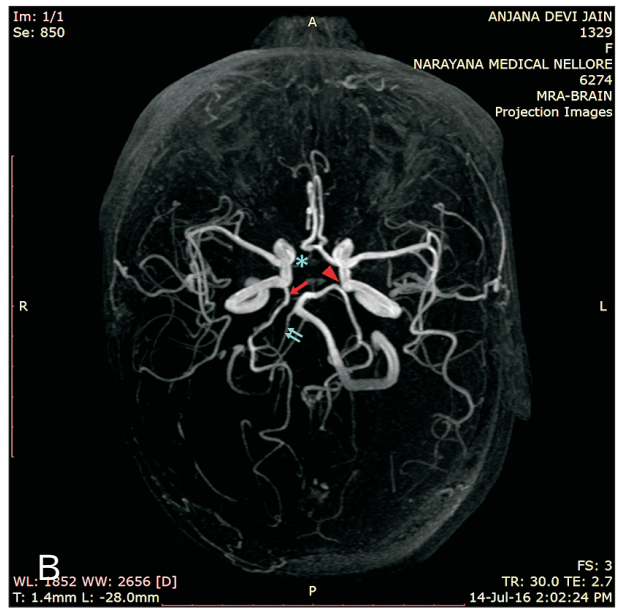

Fig. 4. MRA images showing (A) bilateral PCoA hypoplasia (arrowheads) with hypoplastic right vertebral artery (arrow); (B) left side PCoA hypoplasia (arrowhead) with right fetal type of posterior cerebral artery (arrow); this case also presented hypoplastic right A1 segment of anterior cerebral artery (asterisk) and hypoplastic right vertebral artery (double arrows). MRA, magnetic resonance angiography; $\mathrm{PCoA}$, posterior communicating artery.

Table 2. Cross-tabulation of side and sex-specific incidence of hypoplastic posterior communicating artery patients

\begin{tabular}{|c|c|c|c|c|c|c|}
\hline Side & $\mathrm{N}$ & Male & Female & Total & Chi-square value & $P$-value \\
\hline Left side & Count & 6 & 4 & 10 & \multirow{12}{*}{0.369} & \multirow{12}{*}{$0.831^{\mathrm{a})}$} \\
\hline \multirow{5}{*}{ Right side } & $\%$ within left side & 60.00 & 40.00 & 100.00 & & \\
\hline & $\%$ within sex & 15.38 & 16.67 & 15.87 & & \\
\hline & Count & 9 & 7 & 16 & & \\
\hline & $\%$ within left side & 56.25 & 43.75 & 100.00 & & \\
\hline & $\%$ within sex & 23.08 & 29.17 & 25.40 & & \\
\hline \multirow[t]{3}{*}{ Bilateral } & Count & 24 & 13 & 37 & & \\
\hline & $\%$ within left side & 64.86 & 35.14 & 100.00 & & \\
\hline & $\%$ within sex & 61.54 & 54.17 & 58.73 & & \\
\hline \multirow[t]{3}{*}{ Grand total } & Count & 39 & 24 & 63 & & \\
\hline & $\%$ within left side & 61.90 & 38.10 & 100.00 & & \\
\hline & $\%$ within sex & 100.00 & 100.00 & 100.00 & & \\
\hline
\end{tabular}

N, number of cases observed. ${ }^{\text {a) }} P$-value by Chi-square test, not significant. 
Table 3. Incidence of fetal PCA in relation to sex and side

\begin{tabular}{|c|c|c|c|}
\hline \multirow{2}{*}{ Variable } & \multicolumn{3}{|c|}{ Presence of fetal PCA $(\mathrm{N}=13)$} \\
\hline & Right & Left & $P$-value \\
\hline Male $(\mathrm{n}=154)$ & $3(1.9 \%)$ & $3(1.9 \%)$ & $1.0^{\mathrm{a})}$ \\
\hline Female $(\mathrm{n}=77)$ & $4(5.2 \%)$ & $3(3.9 \%)$ & $0.7^{\mathrm{a})}$ \\
\hline Chi-square value & \multicolumn{2}{|c|}{0.066} & $0.7^{\mathrm{b})}$ \\
\hline
\end{tabular}

PCA, posterior cerebral artery; N, number of fetal PCA cases observed; $P$, difference between the sex and side $\& P<0.05$ is considered significant; $\mathrm{n}$, total number of males or females. ${ }^{\text {a) }}$ Not significant; ${ }^{\text {b) }} P$-value by Chi-square test, not significant; percentages are mentioned within brackets.

circulation between the anterior and posterior part of CW. This artery also acts as an exit port for thalamoperforating artery, in which the important branch is pre-mamillary or thalamotuberal artery [9] which supplies the floor of 3rd ventricle, thalamus, hypothalamus, mammillary bodies, tuber cinereum, optic tract, pituitary stalk, cerebral peduncle and posterior perforated substance [10]. According to a previous report, aplasia of the right PCoA (16.6\%) is more common than the left (3.3\%) which is in accordance with the present study [11]. PCoA hypoplasia was found to have a pathophysiological role in stroke with or without carotid artery occlusion [6]. Out of all the branches of $\mathrm{CW}$, a single branch occlusion might not lead to ischemia, because the collateral supply of that particular region will take over the function [12]. However, PCoA hypoplasia would be prone for the ischemia since its perforating branches might be scarcely perfused in cases of PCoA hypoplasia, predisposing thalamic infarctions leading to lacunar stroke [13]. PCoA hypoplasia as an independent or in association with anterior communicating artery and vertebral artery as observed in the present study can be suggested as a risk factor for ischemic stroke [14, 15].

In a study of classical CW, $10 \%$ of aplasia, hypoplasia or double PCoA have been reported, stressing the importance of PCoA in vertebral artery hypoplasia which results in stroke [16]. However, in the present study double PCoA has not been observed. But one case of vertebral artery hypoplasia along with bilateral PCoA hypoplasia has been noticed. Vertebral artery hypoplasia or occlusion is rarely symptomatic because there will be a sufficient collateral circulation from the contralateral side through CW. But in conditions of bilateral PCoA and one of the vertebral artery hypoplasia, size and patency of these collateral pathways may be a risk factor for developing cerebral infarction [17].

In the present study, 13 cases of f-PCA were observed with the incidence of $5.6 \%$ which is in accordance with the previ- ous literature [18-20].

On the embryological background of CW, the cerebral arteries begin approximately at 5 weeks of gestation. At this stage, many intracranial arteries develop, branch and anastomoses and certain arteries regress among themselves to maintain and to alter towards the adult type of arrangement $[21,22]$. The anterior part of CW originates from ICA which divides into cranial and caudal arteries while the posterior part from bilateral longitudinal neural arteries. The caudal part forms the PCoA, the carotid-vertebrobasilar communicating artery. Initially PCA represents a branch of primitive ICA which then arises from basilar artery when vertebrobasilar system develops as the occipital lobes enlarge and its functional demand increases [23-25]. Around 22 weeks PCoA or P1 segment of PCA may enlarges to meet the supply of posterior cerebral circulation and there found to be a continuous alteration of blood flow between carotid and vertebrobasilar system until the growth of brain is fulfilled. According to Padget [26], embryogenesis of CW takes place in two stages, first development of numerous arterial plexuses and regression of certain arterial segments in-utero or postnatal, transforming itself into adult type [27]. The posterior part of $\mathrm{CW}$ being more anomalous and variant, the posterior part of brain benefit from more blood supply when compared to the anterior part $[28,29]$.

In a study of functional PCoA in posterior circulation ischemia, revealed that the blood flow volume in PCoA can compensate for the decreased flow of BA circulation to a certain degree and play a protective role in posterior cerebral ischemia [30]. According to literature, a complete absence of PCA was never been reported, but its origin from BA or ICA only varies [31].

In the present study bilateral hypoplasia of PCoA was found more than unilateral cases which can be taken into consideration as one of the risk factors for the development of stroke. The percentage of stroke was found to be $60 \%$ in case of bilateral absence of PCoA, $40 \%$ in unilateral absence of PCoA and $20 \%$ in patients having both PCoA [16]. In union with A1 segment of ACA and VA hypoplasia either unilateral or bilateral PCoA can result in headaches, hypertension, vertigo, pulsatile tinnitus and posterior circulation stroke $[32,33]$.

The limitation of the study is that, the difficulty to sort out extremely smaller branches which take part in the collateral circulation to rule out the exact diagnosis such as the CIS. The study also included a limited number of patients 
which in a larger population can provide even much higher rate of variations and a diverse way of diagnostic approach towards PCoA and its associated anomalies.

Under any major arterial occlusion, the collateral circulation plays a key role and takes over the supply of that deficient vessel thereby reducing the risk of stroke or any occlusive diseases of brain. In such conditions, collateral circulation will be more effective when there is a complete CW with the presence of anterior and PCoA. If any one of these vessels is absent or dysfunction, then collateral circulation will be impaired. In ICA occlusion circulation from the contralateral ICA may be achieved by the presence of patent anterior communicating artery [34]. Collateral flow is enabled via the PCoA from the vertebra basilar system thereby aiding perfusion.

Hypoplastic PCoA should be the highly prioritized and monitored arteries in high risk group's patients with brain tumours, trauma injuries and cardiovascular complications.

The PCoA, being the main conduit between internal carotid and vertebrobasilar arterial systems, any type of variation of its own and its related structures such as anterior communicating artery PCA or VA as observed in the present study can be a significant record for clinicians and neurosurgeons intended to neurological procedures.

\section{ORCID}

Sharmila P Bhanu: https://orcid.org/0000-0002-9191-6131

Suneetha Pentyala:

https://orcid.org/0000-0003-4307-3042

Devi K Sankar: https://orcid.org/0000-0001-7025-723X

\section{Author Contributions}

Conceptualization: SPB, SP, DKS. Data acquisition: SP, SPB. Data analysis or interpretation: SPB, SP, DKS. Drafting of the manuscript: SPB, DKS. Critical revision of the manuscript: SPB, SP, DKS. Approval of the final version of the manuscript: all authors.

\section{Conflicts of Interest}

No potential conflict of interest relevant to this article was reported.

\section{References}

1. Eftekhar B, Dadmehr M, Ansari S, Ghodsi M, Nazparvar B, Ketabchi E. Are the distributions of variations of circle of Willis different in different populations? - Results of an anatomical study and review of literature. BMC Neurol 2006;6:22.

2. Bouthillier A, van Loveren HR, Keller JT. Segments of the internal carotid artery: a new classification. Neurosurgery 1996; 38:425-32; discussion 432-3.

3. Roopashree R. A anatomical study on relationship between posterior cerebral artery and posterior communicating artery. Int J Anat Radiol Surg 2013;2:9-12.

4. Krabbe-Hartkamp MJ, van der Grond J, de Leeuw FE, de Groot JC, Algra A, Hillen B, Breteler MM, Mali WP. Circle of Willis: morphologic variation on three-dimensional time-of-flight MR angiograms. Radiology 1998;207:103-11.

5. Feldman BA. Embryology and variations of cerebral arteries- a pictorial review. European Soc Radiol 2013:1-33. doi: 10.1594/ ecr2013/C-2520

6. Chuang YM, Liu CY, Pan PJ, Lin CP. Posterior communicating artery hypoplasia as a risk factor for acute ischemic stroke in the absence of carotid artery occlusion. J Clin Neurosci 2008; 15:1376-81.

7. Pentyala S, Sankar KD, Bhanu PS, Kumar NSS. Magnetic resonance angiography of hypoplastic A1 segment of anterior cerebral artery at 3.0-Tesla in Andhra Pradesh population of India. Anat Cell Biol 2019;52:43-7.

8. Kapoor K, Singh B, Dewan LI. Variations in the configuration of the circle of Willis. Anat Sci Int 2008;83:96-106.

9. Conijn MM, Hendrikse J, Zwanenburg JJ, Takahara T, Geerlings MI, Mali WP, Luijten PR. Perforating arteries originating from the posterior communicating artery: a 7.0-Tesla MRI study. Eur Radiol 2009;19:2986-92.

10. Zwanenburg JJ, Hendrikse J, Takahara T, Visser F, Luijten PR. MR angiography of the cerebral perforating arteries with magnetization prepared anatomical reference at $7 \mathrm{~T}$ : comparison with time-of-flight. J Magn Reson Imaging 2008;28:1519-26.

11. Ardakani SK, Dadmehr M, Nejat F, Ansari S, Eftekhar B, Tajik P, El Khashab M, Yazdani S, Ghodsi M, Mahjoub F, Monajemzadeh M, Nazparvar B, Abdi-Rad A. The cerebral arterial circle (circulus arteriosus cerebri): an anatomical study in fetus and infant samples. Pediatr Neurosurg 2008;44:388-92.

12. Neau JP, Bogousslavsky J. The syndrome of posterior choroidal artery territory infarction. Ann Neurol 1996;39:779-88.

13. Wardlaw JM, Dennis MS, Warlow CP, Sandercock PA. Imaging appearance of the symptomatic perforating artery in patients with lacunar infarction: occlusion or other vascular pathology? Ann Neurol 2001;50:208-15.

14. Chuang YM, Huang YC, Hu HH, Yang CY. Toward a further elucidation: role of vertebral artery hypoplasia in acute ischemic stroke. Eur Neurol 2006;55:193-7.

15. Fischer U, Arnold M, Nedeltchev K, Brekenfeld C, Ballinari P, Remonda L, Schroth G, Mattle HP. NIHSS score and arterio- 
graphic findings in acute ischemic stroke. Stroke 2005;36:21215.

16. Vilimas A, Barkauskas E, Vilionskis A, Rudzinskaite J, Morkunaite R. Vertebral artery hypoplasia: importance for stroke development, the role of posterior communicating artery, possibility for surgical and conservative treatment. Acta Med Litu 2003;10:110-4

17. Park JH, Kim JM, Roh JK. Hypoplastic vertebral artery: frequency and associations with ischaemic stroke territory. J Neurol Neurosurg Psychiatry 2007;78:954-8.

18. De Silva KR, Silva R, De Silva C, Gunasekera WS, Dias P, Jayesekera RW. Comparison of the configuration of the posterior bifurcation of the posterior communicating artery between fetal and adult brains: a study of a Sri Lankan population. Ann Indian Acad Neurol 2010;13:198-201.

19. Sahni D, Jit I, Lal V. Variations and anomalies of the posterior communicating artery in Northwest Indian brains. Surg Neurol 2007;68:449-53.

20. Krishnamurthy A, Nayak SR, Ganesh Kumar C, Jetti R, Prabhu LV, Ranade AV, Rai R. Morphometry of posterior cerebral artery: embryological and clinical significance. Rom J Morphol Embryol 2008;49:43-5.

21. Menshawi K, Mohr JP, Gutierrez J. A functional perspective on the embryology and anatomy of the cerebral blood supply. J Stroke 2015;17:144-58.

22. Caldemeyer KS, Carrico JB, Mathews VP. The radiology and embryology of anomalous arteries of the head and neck. AJR Am J Roentgenol 1998;170:197-203.

23. Abrahams JM, Hurst RW, Bagley LJ, Zager EL. Anterior choroidal artery supply to the posterior cerebral artery distribution: embryological basis and clinical implications. Neurosurgery 1999;44:1308-14.

24. Lasjaunias P, Berenstein A, ter Brugge KG. Intradural Arteries. In: Lasjaunias P, Berenstein A, ter Brugge KG, editors. Clini- cal vascular anatomy and variations. 2nd ed. Berlin: Springer; 2001. p.479-629.

25. Jayaraman MV, Mayo-Smith WW. Multi-detector CT angiography of the intra-cranial circulation: normal anatomy and pathology with angiographic correlation. Clin Radiol 2004;59:690-8.

26. Padge DH. The development of the cranial arteries in the human embryo. Contrib Embryol 1948;32:205-61.

27. Parmar H, Sitoh YY, Hui F. Normal variants of the intracranial circulation demonstrated by MR angiography at 3T. Eur J Radiol 2005;56:220-8.

28. Hoksbergen AW, Fülesdi B, Legemate DA, Csiba L. Collateral configuration of the circle of Willis: transcranial color-coded duplex ultrasonography and comparison with postmortem anatomy. Stroke 2000;31:1346-51.

29. Al-Hussain SM, Shoter AM, Bataina ZM. Circle of Willis in adults. Saudi Med J 2001;22:895-8.

30. Zhou W, Lu M, Li J, Chen F, Hu Q, Yang S. Functional posterior communicating artery of patients with posterior circulation ischemia using phase contrast magnetic resonance angiography. Exp Ther Med 2019;17:337-43.

31. Gunnal SA, Farooqui MS, Wabale RN. Study of posterior cerebral artery in human cadaveric brain. Anat Res Int 2015;2015: 681903.

32. Tuncer MC, Akgül YH, Karabulut Ö. MR angiography imaging of absence vertebral artery causing of pulsatile tinnitus: a case report. Int J Morphol 2010;28:357-63.

33. Vasuki AKM, Devi MN, Jamuna M. Absent intracranial part of right vertebral artery-a case report. Innov J Med Health Sci 2015;5:6-8.

34. Kang DW, Chu K, Ko SB, Kwon SJ, Yoon BW, Roh JK. Lesion patterns and mechanism of ischemia in internal carotid artery disease: a diffusion-weighted imaging study. Arch Neurol 2002; 59:1577-82. 